\title{
Development and Validation of a Pressurization System Model for a Crossfeed Subscale Water Test Article
}

\author{
Han Nguyen* \\ The Boeing Company, Huntington Beach, California, 92647 \\ and \\ Pete Mazurkivich ${ }^{\dagger}$ \\ NASA Marshall Space Flight Center, Huntsville, Alabama, 35812
}

\begin{abstract}
A pressurization system model was developed for a crossfeed subscale water test article using the EASY5 modeling software. The model consisted of an integrated tank pressurization and pressurization line model. The tank model was developed using the general purpose library, while the line model was assembled from the gas dynamic library. The pressurization system model was correlated to water test data obtained from nine test runs conducted on the crossfeed subscale test article. The model was first correlated to a representative test run and frozen. The correlated model was then used to predict the tank pressures and compared with the test data for eight other runs. The model prediction showed excellent agreement with the test data, allowing it to be used in a later study to analyze the pressurization system performance of a full-scale bimese vehicle with cryogenic propellants.
\end{abstract}

\section{Introduction}

$\mathrm{T}$ he Space Launch Initiative (SLI) TA-8 MPS Crossfeed Demonstration project ${ }^{1}$ identified a unique propulsion feed system concept using crossfeed between the Booster and Orbiter stages. Crossfeed refers to the flow of propellants from the Booster tanks to the Orbiter tanks. The crossfeed system allows the Booster and Orbiter engines to draw propellant only from the Booster tanks during the first part of the ascent. After the propellant flow is transitioned to the Orbiter tanks, the Booster is staged, and the Orbiter, with full tanks, proceeds to orbit. This particular design concept uses a passively activated check valve to terminate the flow between the stages ${ }^{2}$. As the Orbiter tank isolation valve is opened to initiate flow from the Orbiter tankage to the Orbiter engines, the difference between the pressure in the main propulsion system (MPS) line and the pressure scheduling of the Orbiter tankage causes the check valve to close. After flow through the crossfeed line is terminated, the disconnects are closed to isolate and seal the crossfeed sections from the exterior. Then the vehicles perform the separation maneuver, and

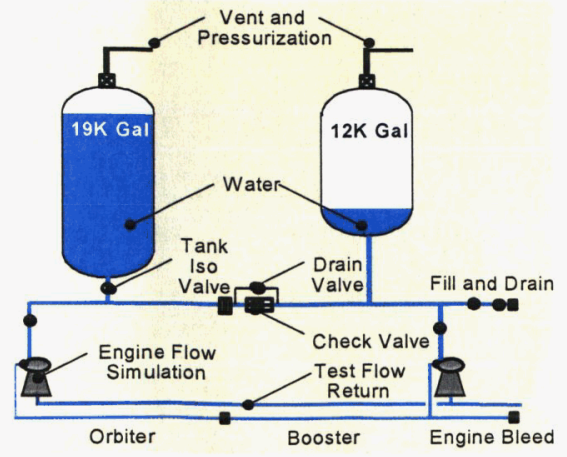

Figure 1. Schematic of Crossfeed Subscale Water Test Article the Orbiter continues on to orbit.

To demonstrate the crossfeed concept, a subscale water test article was designed, built, and tested at the Boeing Huntington Beach B38 water test laboratory, ${ }^{3,4}$ A crossfeed system model was also developed to analyze transient flow in the crossfeed system. This model, which consists of a pressurization system model and a crossfeed flow transient model, was correlated to the test data obtained from the test article. This paper presents the correlation of the pressurization system model to the subscale water test data.

\section{Crossfeed Subscale Water Test Article}

The crossfeed subscale water test article, shown in Fig. 1, uses a 19,000-gallon Integrated Propulsion Technology Demonstrator (IPTD)

*Associate Technical Fellow, TSS Propulsion and Cryogenic Technologies, 5301 Bolsa Ave, MC H012-B201, Associate Fellow AIAA.

${ }^{\dagger}$ Lead Subsystems Manager, Exploration and Transportation Technologies Office, MSFC/ER21. 
liquid hydrogen tank as the Orbiter tank, and the 12,000-gallon IPTD liquid oxygen tank as the Booster tank. Both tanks are 120 inches in diameter, with a length of 453 inches for the 19,000-gallon tank and 286 inches for the 12,000-gallon tank. The tanks are positioned vertically side-by-side in the configuration expected for the Orbiter/Booster assembly. They are pressurized with gaseous nitrogen $\left(\mathrm{GN}_{2}\right)$ from a supply trailer during the water drain operations. The propellant tanks are filled with water from the adjacent B38 1,000,000-gallon underwater test facility. This water is routed back to the underwater test facility to simulate engine flow and conserve water. The engine flow simulators consist of laboratory control valves modified to maintain the required water flows.

\section{Modeling Approach}

The pressurization system model is composed of the tank pressurization model and the pressurization line model, developed and checked out independently before being coupled together. It was developed in parallel with and integrated into the crossfeed flow transient model to form a complete model of the crossfeed water test article from the $\mathrm{GN}_{2}$ supply trailer to the engine flow simulators. Two different approaches were taken in modeling the tank and line as explained in the following sections.

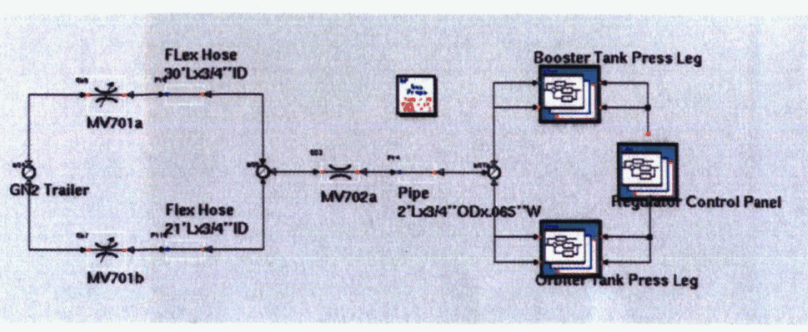

Figure 2. EASY5 diagram of pressurization system model for crossfeed subscale test article

The tank and line models were both developed using the MSC.EASY5 modeling tool (Fig. 2). EASY5 is software used to model, analyze, and design dynamic systems. It is a graphical-userinterface tool that can assemble models from primitive functional blocks (e.g., summers, dividers, integrators) from the general purpose (gp) library, or from application-specific components from the gas dynamics, thermal hydraulic, multiphase fluid libraries, etc. The tank pressurization model was assembled from first principles using the gp library. By taking this approach, the model can be based on the tank pressurization models of the Space Shuttle and Delta IV. Since the models of these vehicles were flight verified and successfully used to predict their pressurization system performances, they provided a solid foundation for the development of the pressurization system model for the crossfeed subscale water test article.

The Booster and Orbiter tank models are identical in layout and differ only in their input data. As shown in Fig. 3, a tank model is assembled from summers, dividers, products, and integrators to perform mathematical operations and numerical integration. These components are connected to Fortran components, tabular functions, and a deadband controller, each with a unique function. The Fortran components calculate the ullage and sump pressures, rate of change of ullage temperature, and internal heat-transfer rates between ullage, liquid, and tank wall; the tabular functions provide the tanking tables, water flow rate profiles, and water properties; and the deadband controller maintains the sump pressure within a control band.

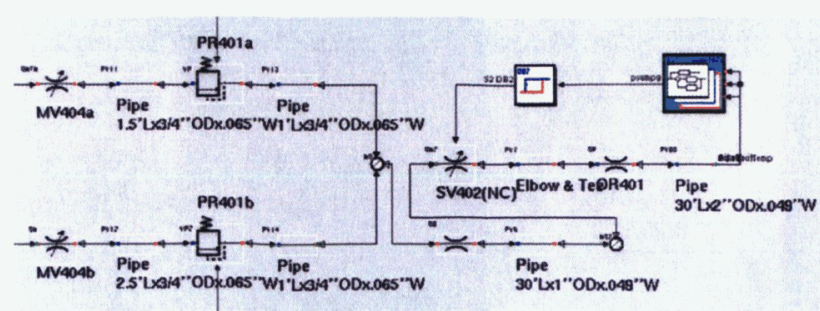

Figure 4. EASY5 diagram of pressurization line model for crossfeed subscale test article

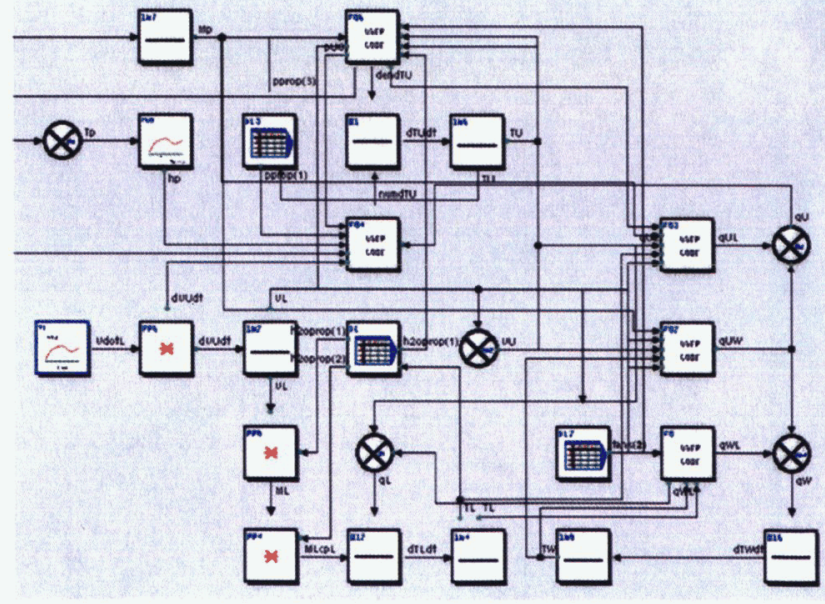

Figure 3. EASY5 diagram of tank pressurization model for crossfeed subscale test article

The pressurization line model was developed using the EASY5 gas dynamic (gd) library. The pressurization line model has three sections, one section to model the $\mathrm{GN}_{2}$ supply from the $\mathrm{GN}_{2}$ trailer to the Booster and Orbiter pressurization legs (Fig. 4), and two sections to model the Booster and Orbiter pressurization legs from the pneumatic panel to the 
tank inlets. Like the tank models, the pressurization legs are identical in layout and differ only in their input data.

The pressurization line model is coupled with the tank pressurization model to form a complete pressurization system from the $\mathrm{GN}_{2}$ trailer to the tank sumps. This coupling allows the tank to exchange information with the pressurization line: the tank signals the solenoid valve to close or open based on its sump pressure, while the pressurization line supplies the tank with pressurant flow to maintain the sump pressure within the control band.

\section{Correlation Approach}

The validation of the pressurization system model consists of a correlation followed by a comparison. In the correlation process, the model is adjusted to give a prediction that meets the requirements for correlation to the test data of a selected test run. In the comparison process, the prediction of the correlated model is visually compared with the test data by overlaying the plots of the data and prediction.

A total of sixty eight tests runs were performed during the crossfeed water tests. Of this total, nine test runs, which included seven fixed engine valve cases and two flight simulation cases (Runs 28R and 29), were chosen for model correlation and comparison. Selected primarily to determine the model capability to predict flow transient phenomenon, these runs cover low (300 gpm), medium (500 gpm), high (800 gpm), and flight simulation flow rates; low (5psi), medium (15 psi), and high ( $25 \mathrm{psi})$ tank pressure differences; and short (0.5 s), medium ( $3 \mathrm{~s})$, and long (7 s) Orbiter isolation valve opening times (Table 1).

Table 1. Test conditions of runs selected for model correlation

\begin{tabular}{llll}
\hline \hline Run & $\begin{array}{l}\text { Booster/Orbiter } \\
\text { flow rate } \\
\text { gpm }\end{array}$ & $\begin{array}{l}\text { Booster/Orbiter } \\
\text { sump pressure } \\
\text { psig }\end{array}$ & $\begin{array}{l}\text { Orbiter valve } \\
\text { opening time } \\
\text { s }\end{array}$ \\
\hline $2 \mathrm{~F}$ & $500 / 500$ & $40 / 55$ & 3 \\
$4 \mathrm{~F}$ & $500 / 500$ & $40 / 55$ & 0.5 \\
$8 \mathrm{~F}$ & $500 / 500$ & $40 / 45$ & 3 \\
$14 \mathrm{~F}$ & $500 / 500$ & $40 / 55$ & 7 \\
$21 \mathrm{~F}$ & $300 / 300$ & $40 / 45$ & 0.5 \\
$28 \mathrm{R}$ & Flight simulation & $40 / 45$ & 3 \\
29 & Flight simulation & $40 / 55$ & 0.5 \\
$33 \mathrm{~F}$ & $800 / 800$ & $40 / 55$ & 0.5 \\
$37 \mathrm{~F}$ & $300 / 300$ & $30 / 55$ & 0.5 \\
engine power level throttle schedule for max Q and flow transition/staging
\end{tabular}

${ }^{1}$ Includes engine power level throttle schedule for max Q and flow transition/staging

The model was correlated to Run $2 \mathrm{~F}$ and then frozen. The correlated model was then run at the conditions of the other test cases. The results of the runs were compared with the test data to determine if they met the correlated model metrics.

The metrics for the correlated pressurization system model were defined by the TA-8 MPS Crossfeed technical performance measures (TPMs) as:

- Requirements $<20 \%$

- Threshold $<30 \%$

- Goal $<10 \%$

Two variables were used in the correlation: (1) Booster and Orbiter sump pressures, and (2) Booster and Orbiter ullage pressures. For each variable, the magnitudes and number of pressurization cycles were compared with the test data. To determine if they met the requirements, threshold, and goal defined above, the maximum percent differences between prediction and test were calculated and compared with the requirements, threshold, and goal.

The maximum percent difference between prediction and test is defined as

$$
\% \Delta y_{\max }=\max \left\{100 \frac{\left|y_{\text {prediction }}-y_{\text {test }}\right|}{y_{\text {test }}}\right\}
$$

where $y$ is the sump pressure, ullage pressure, or number of pressurization cycles. 


\section{Correlation Results}

To correlate the pressurization system model to Run $2 \mathrm{~F}$, the model was provided with inputs obtained from the test data and given in Table 2. These inputs ensured that the prediction and test had the same starting thermodynamic conditions, flow schedules, and sump pressure controls and were compared to each other on the same basis.

Table 2. Pressurization system model inputs

\begin{tabular}{lll}
\hline \hline Input data for Run $2 \mathrm{~F}$ & Booster & Orbiter \\
\hline Initial ullage temperature, $\mathrm{R}$ & 527.7 & 527.4 \\
Initial ullage volume, $\mathrm{ft}^{3}$ & 365.0 & 1296.8 \\
Initial ullage mass, $\mathrm{lb}_{\mathrm{m}}$ & 55.6 & 287.2 \\
Initial liquid temperature, $\mathrm{R}$ & 530.4 & 530.5 \\
Lower control band, psig & 39.2 & 54.2 \\
Upper control band, psig & 40.7 & 54.8 \\
Water flow rate, gpm & actual & actual \\
\hline \hline
\end{tabular}

Using these inputs, the model was run, and the prediction and test data were compared to determine their closeness. The model was then adjusted to obtain the best possible agreement. Since the ullage temperature was used to calculate the ullage pressure, its rate of change had the most effect on the slope of the ullage pressure. This rate of change was affected by the net heat-transfer rate to the ullage, flow work, and energy of the pressurization gas. A close correlation between the prediction and test data was obtained with only an adjustment to the flow work term, which expresses the work done by the ullage gas as it expands during water outflow. This adjustment produced a good match of the slope of the measured ullage pressure for both Booster and Orbiter tanks.

The results of the correlation for Run $2 \mathrm{~F}$ are shown in Fig. 5 for the Booster sump pressure, Fig. 6 for the Booster ullage pressure, Fig. 7 for the Orbiter sump pressure, and Fig. 8 for the Orbiter ullage pressure. Whereas the numbers of pressurization cycles were exactly predicted for both Booster and Orbiter tanks, the maximum difference between prediction and test was $2.83 \%$ for the Booster sump pressure, $3.57 \%$ for the Booster ullage pressure, $0.26 \%$ for the Orbiter sump pressure, and $0.49 \%$ for the Orbiter ullage pressure. These differences met the requirement, threshold, and goal of the TPM for model accuracy, and the pressurization system model was correlated to Run $2 \mathrm{~F}$.

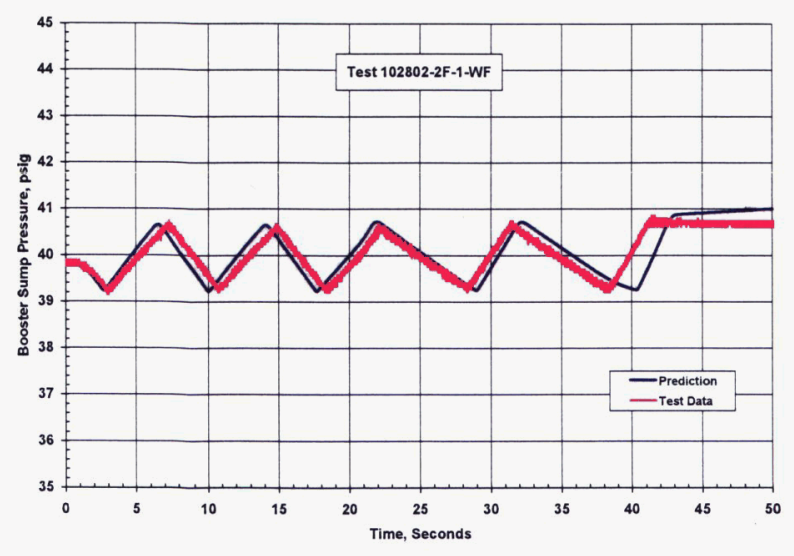

Figure 5. Booster sump pressure (Run 2F)

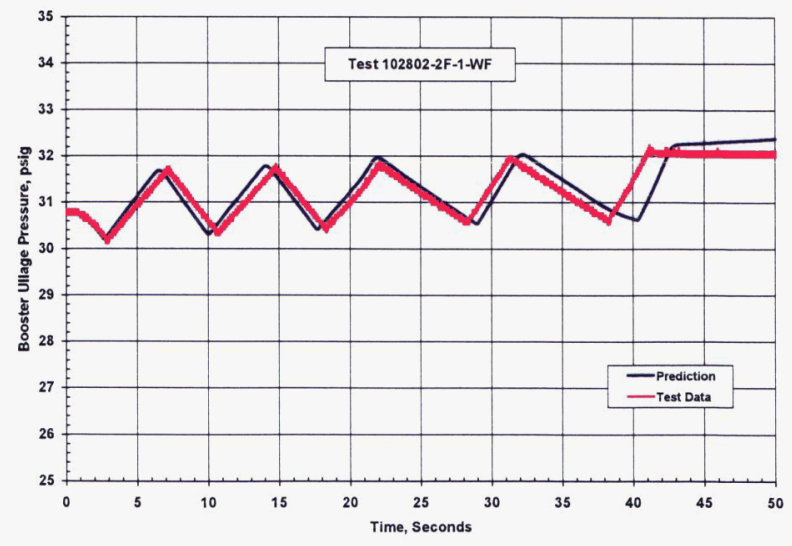

Figure 6. Booster ullage pressure (Run 2F) 


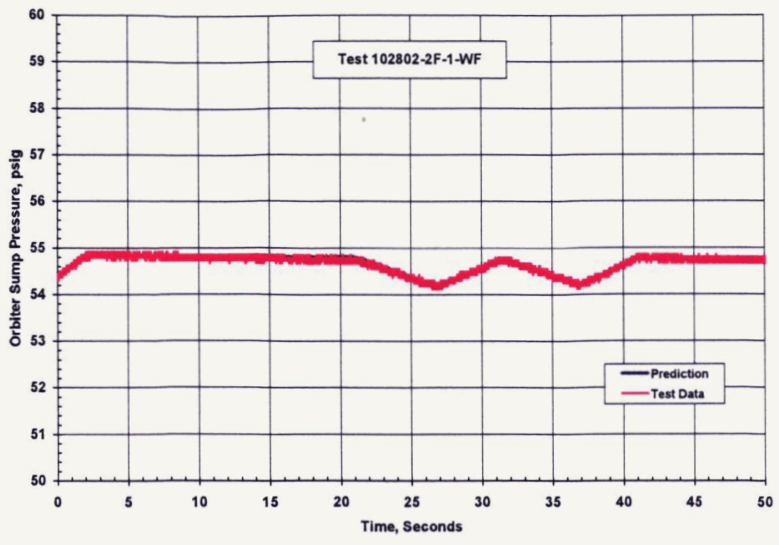

Figure 7. Orbiter sump pressure (Run 2F)

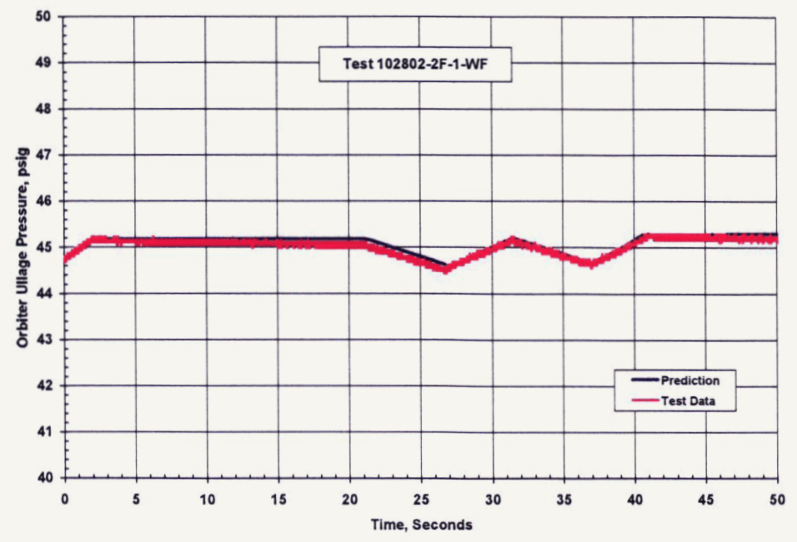

Figure 8. Orbiter ullage pressure (Run 2F)

\section{Prediction and Test Data Comparison}

Using the correlated model, now frozen, predictions were made for Runs $4 \mathrm{~F}, 8 \mathrm{~F}, 14 \mathrm{~F}, 21 \mathrm{~F}, 28 \mathrm{R}, 29,33 \mathrm{~F}$, and $37 \mathrm{~F}$ using the inputs listed in Section V. The prediction and test data for the Booster and Orbiter sump pressures and Booster and Orbiter ullage pressures were plotted and compared to determine their closeness. Two cases were shown as examples: Run 4F in Figs. 9 through 12 for a fixed engine valve case, and Run 28R in Figs. 13 through 16 for a flight simulation case. These two cases are typical of the eight comparison runs.

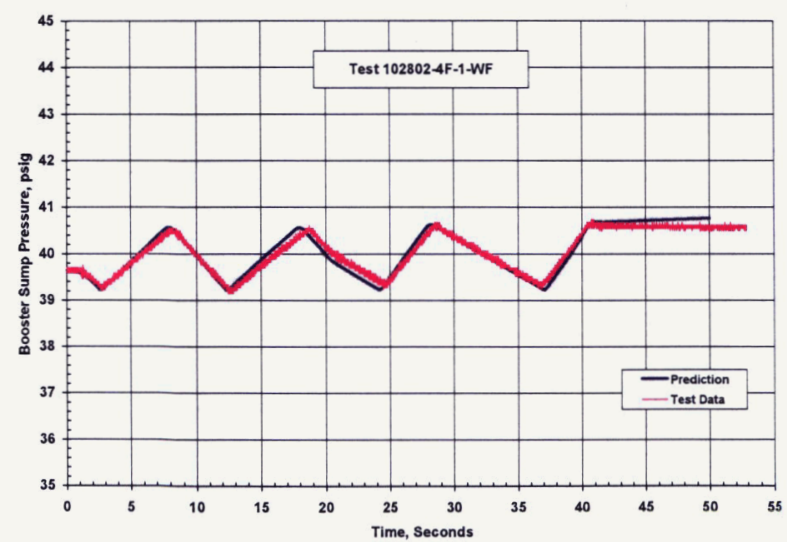

Figure 9. Booster sump pressure (Run 4F)

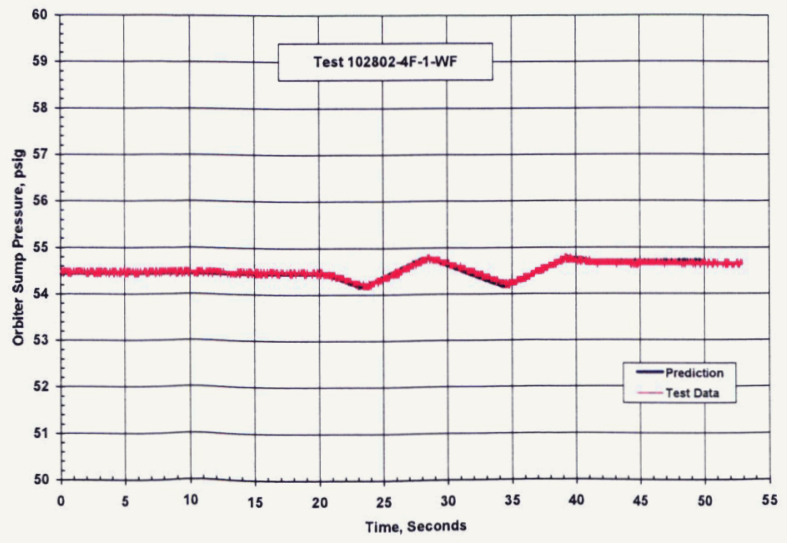

Figure 11. Orbiter sump pressure (Run 4F)

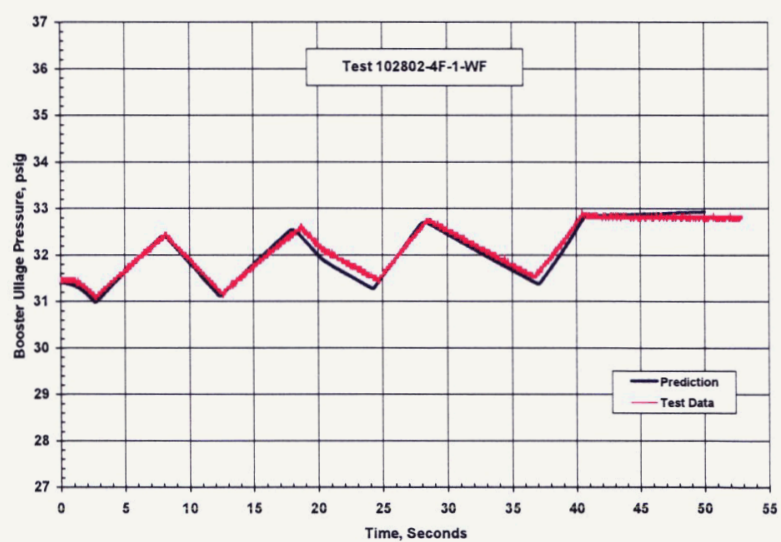

Figure 10. Booster ullage pressure (Run 4F)

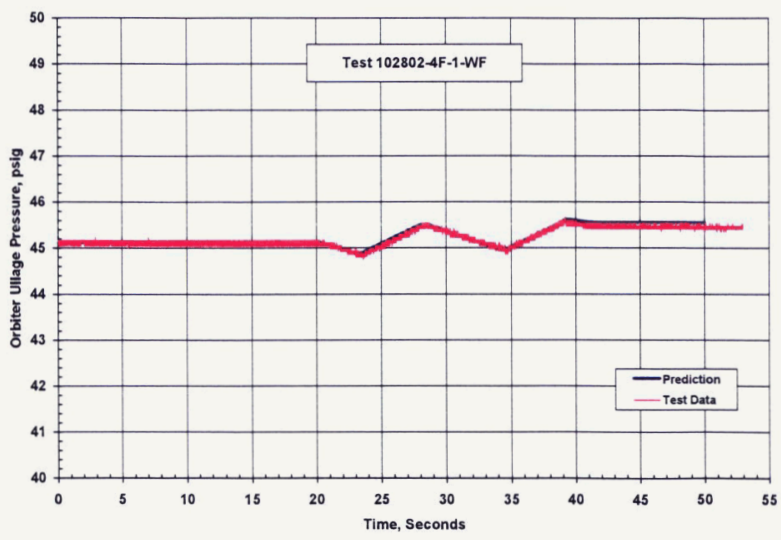

Figure 12. Orbiter ullage pressure (Run 4F) 


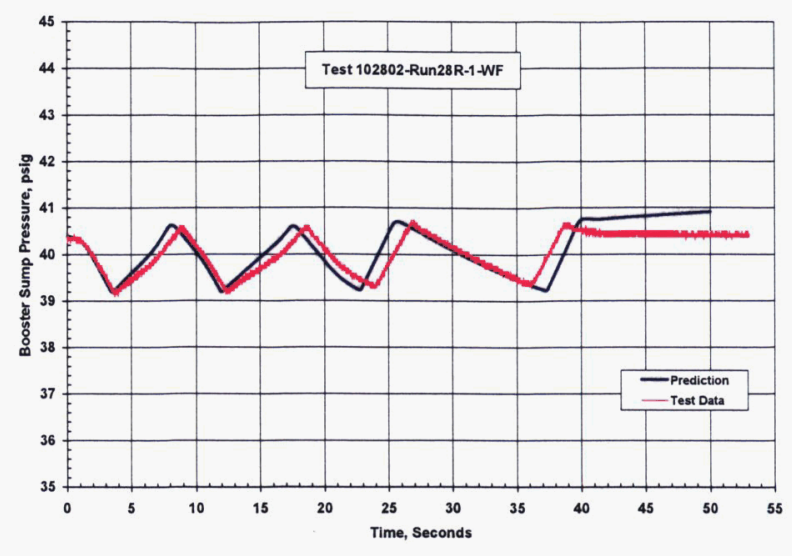

Figure 13. Booster sump pressure (Run 28R)

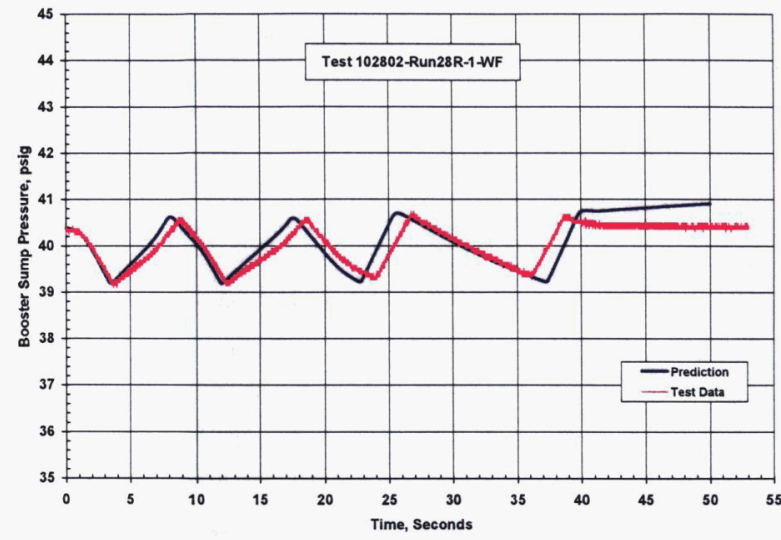

Figure 15. Orbiter sump pressure (Run 28R)

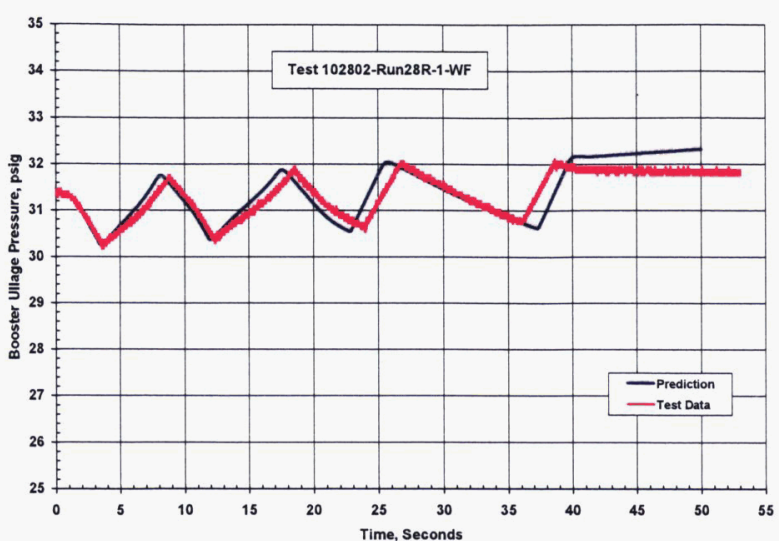

Figure 14. Booster ullage pressure (Run 28R)

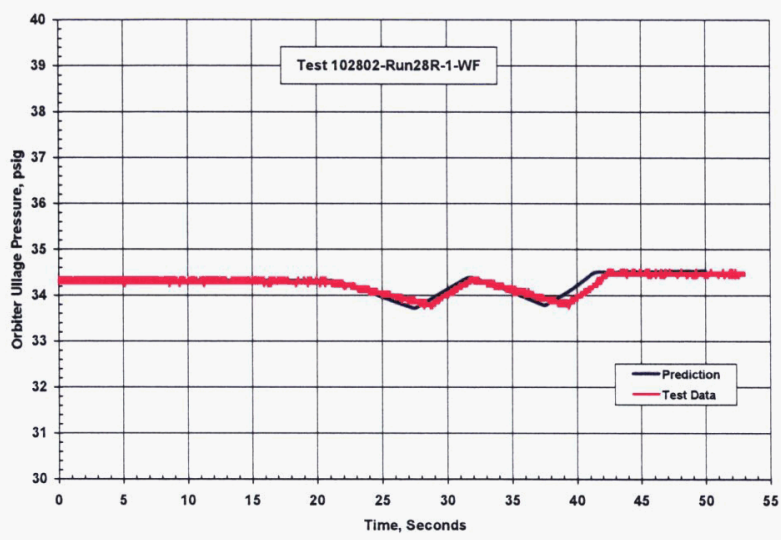

Figure 16. Orbiter ullage pressure (Run 28R)

The maximum percent differences between the prediction and test data for the correlation run and the eight comparison runs are given in Table 3. The sump and ullage pressures achieve excellent agreement, while the number the pressurization cycles is exactly predicted for all runs:

- The Booster sump pressures agree within 3\% (2.98\% max difference for Run $21 \mathrm{~F}$ )

- The Booster ullage pressures agree within 4\% (3.57\% max difference for Run $2 \mathrm{~F})$

- The Orbiter sump pressures agree within $2 \%$ (1.63\% max difference for Run $21 \mathrm{~F})$

- The Orbiter ullage pressures agree within 2\% (1.95\% max difference for Run $21 \mathrm{~F})$

As with the correlation run, the comparison runs met the requirements, threshold, and goal defined by the TPMs in terms of sump and ullage pressures and number of pressurization cycles on both Booster and Orbiter sides.

Table 3. Maximum percent differences between prediction and test data

\begin{tabular}{|c||c|c|c|c||r|r|r|r|}
\hline \multicolumn{1}{|c||}{ Test Run } & \multicolumn{3}{c||}{$\%$ Pressure Difference } & \multicolumn{2}{c|}{ \% Difference in No of Press Cycles } \\
\hline \multicolumn{1}{|c|}{} & \multicolumn{2}{|c|}{ Booster } & \multicolumn{2}{c|}{ Orbiter } & \multicolumn{2}{c|}{ Booster } & \multicolumn{2}{|c|}{ Orbiter } \\
\cline { 2 - 8 } & Sump & Ullage & Sump & Ullage & Sump & Ullage & Sump & Ullage \\
\hline $2 \mathrm{~F}$ & 2.83 & 3.57 & 0.26 & 0.49 & 0 & 0 & 0 & 0 \\
$4 \mathrm{~F}$ & 0.74 & 1.11 & 0.30 & 0.43 & 0 & 0 & 0 & 0 \\
$8 \mathrm{~F}$ & 2.08 & 2.42 & 0.81 & 1.17 & 0 & 0 & 0 & 0 \\
$14 \mathrm{~F}$ & 0.89 & 1.07 & 0.38 & 0.43 & 0 & 0 & 0 & 0 \\
$21 \mathrm{~F}$ & 2.98 & 3.40 & 1.63 & 1.95 & 0 & 0 & 0 & 0 \\
$28 \mathrm{R}$ & 1.93 & 2.60 & 0.92 & 1.01 & 0 & 0 & 0 & 0 \\
29 & 1.30 & 1.63 & 0.39 & 0.47 & 0 & 0 & 0 & 0 \\
$33 \mathrm{~F}$ & 1.00 & 1.12 & 0.42 & 0.37 & 0 & 0 & 0 & 0 \\
$37 \mathrm{~F}$ & 0.76 & 0.78 & 0.26 & 0.44 & 0 & 0 & 0 & 0 \\
\hline
\end{tabular}




\section{Conclusions}

The pressurization system model developed on EASY5 for the crossfeed subscale water test article was correlated to the test data of a selected run: the sump and ullage pressures were correlated within $4 \%$, while the number of pressurization cycles was exactly predicted for this run. The correlated model was then used to simulate eight other test runs with varying flow rates, tank pressure differences, and Orbiter valve closing times. In each case, the model predicted the sump and ullage pressures within $4 \%$ and the number of pressurization cycles exactly. By meeting the requirements, threshold, and goal defined by the TPMs for model accuracy, the pressurization system model for the crossfeed subscale water test article was validated. In a subsequent study, it was upgraded to that of a full-scale vehicle and used to analyze the pressurization system performance of a generic bimese TwoStage to-Orbit Reusable Launch Vehicle ${ }^{6}$.

\section{Acknowledgments}

The work reported in this paper was performed under NASA Contract No. NAS8-01099, TA-8 MPS Crossfeed Demonstration, for NASA Marshall Space Flight Center. Mr. Shayne Swint, Contracting Officer Technical Representative Designee; Dr. Tom Brown, Lead System Engineer; Mr. Pete Mazurkivich, Lead Subsystem Manager; and Mr. Chris Popp, Engineering Lead, provided the technical leadership at NASA. Dr. Frank Chandler, Principal Investigator, provided the leadership for the Boeing TA-8 technical team.

\section{References}

${ }^{1}$ Chandler, F., Scheiern, M., Champion, R., and Mazurkivich, P., "Launch Vehicle Sizing Benefits Utilizing Main Propulsion System Crossfeed and Project Status," AIAA Paper 2002-3900, July 2002.

${ }^{2}$ Chandler, F., Grayson, G., and Mazurkivich, P., "The Importance of Detailed Component.Simulations in the Feedsystem Development for a Two-Stage-to-Orbit Reusable Launch Vehicle," AIAA Paper 2005-4370, July 2005.

${ }^{3}$ Chandler, F., et al., "TA-8 MPS Crossfeed Demonstration Final Report Through Option 1 Period," PWDM03-0076, The Boeing Company, 30 May 2003.

${ }^{4}$ Chandler, F., et al., "TA-8 MPS Crossfeed Demonstration Summary Report," PWDM03-0123, The Boeing Company, 30 May 2003.

${ }^{5}$ Tollefson, J., EASY5 User's Guide, The Boeing Company, September 1996.

${ }^{6}$ Nguyen, H., Chandler, F., and Mazurkivich, P., "Pressurization System Modeling for a Generic Bimese Two-Stage-to-Orbit Reusable Launch Vehicle," AIAA Paper 2005-4371, July 2005. 